\title{
Myofascial pain associated to trigger points: A literature review. Part 2: Differential diagnosis and treatment
}

\author{
Eduardo Vázquez-Delgado ${ }^{1}$, Jordi Cascos-Romero ${ }^{2}$, Cosme Gay-Escoda ${ }^{3}$
}

${ }^{1}$ DDS. Master of Science in Orofacial Pain, University of Kentucky Dental School (USA). Associate Professor and Coordinating Professor of the TMJ Disease and Orofacial Pain Unit of the Master of Oral Surgery Degree Program. University of Barcelona Dental School. Member of the TMJ Disease and Orofacial Pain Unit. Teknon Medical Center. Barcelona (Spain)

${ }^{2}$ DDS. Associate Professor and Collaborating Professor of the Master of Oral Surgery Degree Program. University of Barcelona Dental School

${ }^{3}$ DDS, MD, PhD. Chairman of Oral and Maxillofacial Surgery. Director of the Master of Oral Surgery and Implantology Degree Program. University of Barcelona Dental School. Head of the Service of Oral Surgery, Implantology and Maxillofacial Surgery, and Codirector of the TMJ Disease and Orofacial Pain Unit. Teknon Medical Center. Barcelona (Spain)

Correspondence:

Centro Médico Teknon

C/Vilana 12

08022 - Barcelona (Spain)

cgay@bell.ub.es

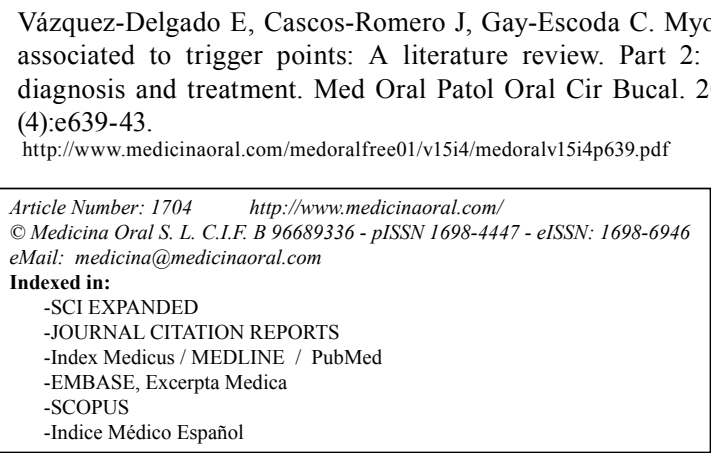

\begin{abstract}
During the last decades the advance in knowledge of myofascial pain has been constant in the medical and dental community. However, although several aspects have been clarified in relation to its epidemiology, clinical characteristics and etiopathogenesis, many uncertainties remain. Many clinical conditions are included in the differential diagnosis of myofascial pain associated to trigger points. A good anamnesis and clinical exploration is thus required in order to ensure correct diagnosis and treatment. Among the numerous treatments used in application to trigger points, the spray-and-stretch technique and direct injection targeted to such trigger points have been found to be the most effective options. In chronic cases, psychosocial intervention is required, due to the high incidence of mood disorders and/or anxiety observed in these patients, who in turn present a poorer prognosis. This underscores the importance of early diagnosis and treatment.
\end{abstract}

Key words: Myofascial pain, trigger point, craniomandibular disorders. 


\section{Introduction}

Myofascial pain associated to trigger points (TPs) has been investigated by the medical and dental community for over a century. However, different aspects relating to its physiopathology, clinical presentation and treatment remain to be clarified $(1,2)$.

It has been difficult to establish diagnostic criteria and specific treatment protocols for myofascial pain syndrome, since most studies to date have grouped patients with different musculoskeletal disorders, due to a lack of consensus over the corresponding screening criteria (1). The present study describes myofascial pain based on the main characteristics reported in the literature regarding the differential diagnosis and treatment of this disorder.

\section{Differential Diagnosis}

A range of disorders have been included in the differential diagnosis of myofascial pain (Table 1) $(3,4)$, though fibromyalgia, cervical joint dysfunction, non-myofascial trigger points and post-traumatic hyperirritability syndrome (PHS) are the conditions most often wrongly diagnosed as myofascial pain (4).

Table 1. Clinical conditions included in the differential diagnosis of pain trigger points $(3,4)$.

a) Non-myofascial trigger point (fibromyalgia)

b) Musculoskeletal diseases:

- Temporomandibular joint disorders

- Occupational myalgias

- Post-traumatic hyperirritability syndrome

- Joint dysfunction (osteoarthritis)

- Tendonitis and bursitis

c) Neurological disorders:

- Trigeminal neuralgia

- Glossopharyngeal neuralgia

- Sphenopalatine neuralgia

d) Systemic diseases

- Rheumatoid arthritis

- Gout

- Psoriatic arthritis

- Infections (viral, bacterial and/or protozoan)

e) Heterotopic pain of central origin

f) Axis II-type disorders:

- Psychogenic pain

- $\quad$ Painful behaviors

g) Drug reactions
Fibromyalgia (FM) is a chronic disease characterized by pain in multiple body locations and generalized tiredness. It is a common disorder, found in $1-3 \%$ of the general population $(5,6)$, and can manifest as a single disorder (primary fibromyalgia) or associated to other illnesses (concomitant fibromyalgia). In this context, fibromyalgia may be concomitantly present in over $50 \%$ of all patients with myofascial pain associated to TPs (7).

Some theories have implicated alterations in neurotransmitter regulation, immune function, sleep physiology or hormonal control in the pathogenesis of fibromyalgia all associated to dysfunction of the limbic system and neuroendocrine axis $(5,8,9)$.

It is necessary to distinguish the painful points of fibromyalgia from the TPs of myofascial pain, since activation of the latter causes referred pain and central excitation phenomena, whereas stimulation of the painful points in fibromyalgic patients does not produce such symptoms (Table 2) (4-7).

Non-myofascial TPs can be located in skin, tendons, fascias, scars and ligaments, and can induce referred pain phenomena similar to those described in myofascial pain. In both cases the proposed treatment is the same, though there is no evidence of any kind that the referred pain patterns of non-myofascial TPs are analogous to those found in patients with myofascial pain. An important difference between the two diseases is the absence of palpable hypersensitive nodules in the nonmyofascial TP zones (1-3).

Post-traumatic hyperirritability syndrome (PHS) is found in a limited group of patients with myofascial pain, where important sensory irritability is observed as a result of severe head and neck injuries (generally due to traffic accidents). The pain in these subjects tends to be constant, though they may present an increase in motor activity as a result of the loss of supraspinal inhibition, giving rise to muscle spasms in response to any intense sensory stimulus. PHS can be mistakenly diagnosed as a psychological disorder on the basis of the absence of organic alterations capable of accounting for the symptoms $(3,10)$.

Joint dysfunction represents one of the musculoskeletal pain syndromes that most often produce muscle pain $(3,7)$. In this case the increase in muscle tension and activity associated to TPs can perpetuate or provoke joint stress, while in some cases joint stress can cause TP activation. Thus, joint treatment of the joint and muscle disorders is essential if both conditions are assumed to coexist (3).

\section{Treatment}

The spray-and-stretch technique and punction-injection of the TPs constitute the treatment modalities of choice, in view of their efficacy in eliminating the TPs $(1,2,11)$. 
Table 2. Differences and similarities between trigger points and tender points (4-7).

\begin{tabular}{|c|c|c|}
\hline & TRIGGER POINTS & TENDER POINTS \\
\hline Gender distribution & $1: 1$ & 4-9 females: 1 male \\
\hline $\begin{array}{l}\text { Physical character- } \\
\text { istics }\end{array}$ & $\begin{array}{l}\text { Muscular, tense bands, referred } \\
\text { pain, reproducible pain, irritability }\end{array}$ & $\begin{array}{l}\text { Tender areas in muscles, tendons, liga- } \\
\text { ments, joint capsules }\end{array}$ \\
\hline Distribution & $\begin{array}{l}\text { Focal-asymmetrical. Located in any } \\
\text { muscle }\end{array}$ & $\begin{array}{l}\text { Generalized-symmetrical. Concrete loca- } \\
\text { tions }\end{array}$ \\
\hline Pain pattern & $\begin{array}{l}\text { Regional pain } \\
\text { Focal tenderness }\end{array}$ & $\begin{array}{l}\text { Generalized pain } \\
\text { Generalized tenderness }\end{array}$ \\
\hline Skin fold sensitivity & Not known & Often present \\
\hline Mobility & Restricted movement range & Hypermobility \\
\hline Histology & No specific changes in biopsy & No specific changes in biopsy \\
\hline Palpation & $\begin{array}{l}\text { Rigid muscle palpation (palpable } \\
\text { nodules) }\end{array}$ & Soft and flaccid muscle palpation \\
\hline Algometry & $\begin{array}{l}\text { Threshold } 2 \mathrm{~kg} / \mathrm{cm}^{2} \text { over adjacent } \\
\text { normal zones }\end{array}$ & $4 \mathrm{~kg}$ pressure \\
\hline Reliability index & $\begin{array}{l}\text { Good in pain in response to palpa- } \\
\text { tion and with algometry; poor in rest }\end{array}$ & Good in relation to pain or algometry \\
\hline MRI findings & No data & No morphological changes \\
\hline Electromyography & $\begin{array}{l}\text { Spontaneous activity at trigger } \\
\text { points } 1 \text { or } 2 \mathrm{~mm}\end{array}$ & $\begin{array}{l}\text { No denervation } \\
\text { No muscle spasm }\end{array}$ \\
\hline $\begin{array}{l}\text { Allodynia / hyperal- } \\
\text { gesia }\end{array}$ & Only present at trigger points & At tender points and other control sites \\
\hline $\begin{array}{l}\text { Treatment with local } \\
\text { injection }\end{array}$ & Immediate response to injections & Poor response to injections \\
\hline Comorbidity & $20 \%$ have fibromyalgia & $72 \%$ have active trigger points \\
\hline
\end{tabular}

The spray-and-stretch technique allows treatment of an extensive anatomical territory, favoring the simultaneous recovery of several muscles $(2,12)$. The objective is to cool the muscle in its entire extent by applying a vaporized cooling liquid, followed by passive stretching of the treated muscle (2).

In this context fluori-methane is the vaporized coolant of choice for the treatment of myofascial pain, since it is noninflammable, chemically stable and not toxic for the patient. However, the negative environmental impact of this agent has led to the search for alternatives (2).

Most authors recommend placing the vaporizer at a distance of about $45 \mathrm{~cm}$ from the skin, and at an angle of 30 degrees $(1,2,4)$. The vaporizing substances are applied as a fine stream or jet, since efficacy in spray form is limited. The jet is directed in a single direction (caudad to cranial) towards and including the affected zone. Once the treatment has been applied, relative rest of the treated zones is advised for two or three days, with muscle stretching and strengthening exercises (isotonic and isometric). The application of warmth with a cloth is advised at the end of each vaporizing cycle (2).
The inactivation of myofascial TPs through the injection of local anesthetics is one of the most important management options. The mechanism of action is based on the disruption and inactivation of the active "locus" of the TP (1, 12-14). Local anesthetics are used only for reducing the post-injection pain that usually accompanies injection of the TPs $(13,14)$. Some authors prefer the "dry" puncture technique, since the use of local anesthetics complicates the location of TPs adjacent to the injection zone (12). Most studies have shown no statistically significant differences between injection with local anesthetic and the "dry" puncture technique in eliminating TPs $(11,15)$, and Kamanli et al. (13) have even concluded that the latter is more effective and faster acting than anesthetic inoculation.

Procaine is the local anesthetic offering the best results in infiltrating TPs $(2,3)$. Its main advantages are short action (15-20 minutes) and minimal systemic toxicity, with the absence of local irritation. Other local anesthetic agents such as lidocaine, prilocaine, mepivacaine and bupivacaine $(1,12,16-18)$, and more recently also levobupivacaine and ropivacaine (15), have been cited 
in the literature for the management of myofascial pain. The ideal local anesthetic concentration is $0.5 \%$, since higher concentrations do not afford significant therapeutic advantages $(2,13,16)$. Local anesthetic infiltration is always carried out without a vasoconstrictor, and the use of bisulfite in the anesthetic preparation is to be avoided, since it causes post-injection sensitivity and pain $(2,18)$

The anesthetic solution can be replaced in the injection solution by corticosteroids, nonsteroidal antiinflammatory drugs and/or type A botulin toxin $(12,13,15,16,19)$, though the latter is exclusively used in patients who are resistant to the conventional treatment (20).

During TP injection it is advisable to place the patient in a reclined position, to avoid the appearance of vasovagal syndrome $(2,12)$. It is essential to apply a local antiseptic (alcohol, povidone iodine, etc.) in the muscle zone before injection, and injection or puncture in areas with skin or muscle infection or susceptible to infection must be avoided (2).

The needles used are of gauges 21 and 22, with a length of $7.6 \mathrm{~cm}$, though a 25 gauge needle is preferred in very painful zones or in patients with capillary fragility. The needle is to be inserted no more than two-thirds of its length, in order to avoid the risk of fracture in the event of sudden movement $(2,12)$. The traditional TP injection technique involves firming or tensing the skin at the injection site and inserting the needle perpendicular to the surface of the skin (2).

After the injection, the local and referred pain decreases for a period of approximately 7 days, after which it gradually increases again - though without reaching the initial intensity before treatment. As a result, several sessions are needed to achieve lasting effects $(2,11,13)$. The appearance of ecchymosis and inflammation after injection is common. Damage to important structures surrounding the injection site is infrequent, provided we have good anatomical knowledge of the zone. Damage to nerve endings is uncommon - thereby limiting the risk of motor or sensory alterations. TP treatment with local injections or puncture is absolutely contraindicated in patients subjected to anticoagulant therapy, and special precautions are required in smokers $(2,21)$.

However, Shen et al. (22) have suggested that pain reduction in the treatment of TPs as a result of nociceptive stimulation is not dependent upon the location of the stimulus but on the stimulus itself. In any case, Tough et al. (14) have indicated that the heterogeneity of the studies published to date does not allow the drawing of significant conclusions regarding the effectiveness of puncture therapy versus placebo.

The terms "ischemic compression" and "myotherapy" have been used to describe treatment in which ischemia is induced in the TP zone by applying sustained digital pressure. However, this principle is rather meaning- less, since the nucleus of the trigger point intrinsically presents important hypoxia $(2,3)$.

Simons et al. (2) described a similar treatment modality, though without the need to induce additional ischemia in the TP zone. The aim of this technique is to free the contracted sarcomeres within the TP. The amount of pressure applied should suffice to produce gradual relaxation of the tension within the TP zone, without causing pain. Some authors suggest that certain forms of acupuncture (shiatsu) have analogies with this treatment modality (14). Deep massage may prove effective in eliminating TPs when performed by experienced professionals. In this context, it is the most effective manual method in the treatment of myofascial pain. It therapeutic principle is similar to that of the sustained pressure technique $(2,17,23)$.

Ultrasound, iontophoresis, phonophoresis and highvoltage galvanic stimulation are used by many professionals for the treatment of myofascial pain, though none of these techniques are supported by scientific evidence of their efficacy in eliminating TPs. As such, they are regarded as coadjuvant therapies $(2,24-26)$. In the same way, transcutaneous electric nerve stimulation (TENS), drug treatment and/or cryo-thermotherapy are only useful for controlling the pain symptoms that accompany myofascial pain (27). Nevertheless, the effectiveness of these techniques tends to decrease in the treatment of chronic myofascial pain (17). At present, low-power laser irradiation has been proposed for the treatment of TPs, though the results obtained have not been superior to those recorded in the placebo group (28).

The administration of nonsteroidal antiinflammatory drugs is of some use in controlling post-injection pain in the context of TP therapy $(2,3,12)$. The use of muscle relaxants in the management of musculoskeletal diseases has been based on the wrong conception that muscle pain induces spasms in the affected muscle tissue. In this context, normal electromyographic activity has been demonstrated in patients with muscle pain - thus invalidating the above idea $(1,29)$.

The administration of antihistamines, tricyclic antidepressants and natural hormones such as melatonin is recommended in myofascial pain characterized by the presence of sleep disturbances (2). The consumption of alcohol, caffeine and nicotine is contraindicated in patients of this kind, since these substances can worsen the symptoms of myofascial pain by inducing sleep disturbances and increased sympathetic activity (1-3, 21). Vignolo et al. (30) have reported that oral contraceptive use is associated to lesser pain levels in patients with TPs, though the reason for such a reduction in pain was not commented.

The prognosis of myofascial pain is directly related to the duration of the condition. As a result, an early diagnosis is fundamental. In general, acute muscle injuries 
with defined etiological factors offer a favorable prognosis, provided they are treated in time. Patients with referred pain that proves stable over time and without spread to adjacent muscles respond better to treatment than patients with progressive worsening of their symptoms (1-3). In any case, and regardless of the treatment administered, it is necessary to eliminate as many perpetuating factors as possible, provide adequate postural instructions for the patients, and prescribe an exercise program to be carried out at home, with a view to reducing or eliminating the chronic pain $(17,23)$.

\section{References}

1. Lavelle ED, Lavelle W, Smith HS. Myofascial trigger points. Anesthesiol Clin. 2007;25:841-51.

2. Simons DG, Travell JG, Simons LS, Travell JG. Travell \& Simons' myofascial pain and dy function: the trigge point manual. 2th ed. Baltimore: Williams \& Wilkins; 1999.

3. Okeson JP, Bell WE. Pains of muscle origin. Bell's Orofacial pains. Chicago: Quintessence Pub.Co, 1995: 259-94.

4. Poveda Roda R, Bagan JV, Díaz Fernández JM, Hernández Bazán S, Jiménez Soriano Y. Review of temporomandibular joint pathology. Part I: classification, epidemiology and risk factors. Med Oral Patol Oral Cir Bucal. 2007;12:E292-8.

5. Schneider MJ. Tender points/fibromyalgia vs. trigger points/myofascial pain syndrome: a need for clarity in terminology and differential diagnosis. J Manipulative Physiol Ther. 1995;18:398-406.

6. Jäckel WH, Genth E. [Fibromyalgia]. Z Rheumatol. 2007;66:57990.

7. Leblebici B, Pektaș ZO, Ortancil O, Hürcan EC, Bagis S, Akman MN. Coexistence of fibromyalgia, temporomandibular disorder, and masticatory myofascial pain syndromes. Rheumatol Int. 2007;27:541-4.

8. Bennett RM, Cook DM, Clark SR, Burckhardt CS, Campbell SM. Hypothalamic-pituitary-insulin-like growth factor-I axis dysfunction in patients with fibromyalgia. J Rheumatol. 1997;24:1384-9.

9. Moldofsky HK. Disordered sleep in fibromyalgia and related myofascial facial pain conditions. Dent Clin North Am. 2001;45:701-13. 10. Amital D, Fostick L, Polliack ML, Segev S, Zohar J, Rubinow A, et al. Posttraumatic stress disorder, tenderness, and fibromyalgia syndrome: are they different entities? J Psychosom Res. 2006;61:663-9. 11. Hsieh YL, Kao MJ, Kuan TS, Chen SM, Chen JT, Hong CZ. Dry needling to a key myofascial trigger point may reduce the irritability of satellite MTrPs. Am J Phys Med Rehabil. 2007;86:397-403.

12. Cummings TM, White AR. Needling therapies in the management of myofascial trigger point pain: a systematic review. Arch Phys Med Rehabil. 2001;82:986-92.

13. Kamanli A, Kaya A, Ardicoglu O, Ozgocmen S, Zengin FO, Bayik Y. Comparison of lidocaine injection, botulinum toxin injection, and dry needling to trigger points in myofascial pain syndrome. Rheumatol Int. 2005;25:604-11.

14. Tough EA, White AR, Cummings TM, Richards SH, Campbell JL. Acupuncture and dry needling in the management of myofascial trigger point pain: a systematic review and meta-analysis of randomised controlled trials. Eur J Pain. 2009;13:3-10.

15. Zaralidou AT, Amaniti EN, Maidatsi PG, Gorgias NK, Vasilakos DF. Comparison between newer local anesthetics for myofascial pain syndrome management. Methods Find Exp Clin Pharmacol. 2007;29:353-7.

16. Ga H, Choi JH, Park CH, Yoon HJ. Acupuncture needling versus lidocaine injection of trigger points in myofascial pain syndrome in elderly patients--a randomised trial. Acupunct Med. 2007;25:130-6.

17. Hong CZ. Treatment of myofascial pain syndrome. Curr Pain Headache Rep. 2006;10:345-9.

18. Iwama H, Ohmori S, Kaneko T, Watanabe K. Water-diluted local anesthetic for trigger-point injection in chronic myofascial pain syndrome: evaluation of types of local anesthetic and concentrations in water. Reg Anesth Pain Med. 2001;26:333-6.

19. Porta M. A comparative trial of botulinum toxin type A and methylprednisolone for the treatment of tension-type headache. Curr Rev Pain. 2000;4:31-5.

20. Ho KY, Tan KH. Botulinum toxin A for myofascial trigger point injection: a qualitative systematic review. Eur J Pain. 2007;11:51927.

21. Blee TH, Cogbill TH, Lambert PJ. Hemorrhage associated with vitamin C deficiency in surgical patients. Surgery. 2002;131:408-12. 22. Shen YF, Goddard G. The short-term effects of acupuncture on myofascial pain patients after clenching. Pain Pract. 2007;7:256-64. 23. Orlando B, Manfredini D, Bosco M. Efficacy of physical therapy in the treatment of masticatory myofascial pain: a literature review. Minerva Stomatol. 2006;55:355-66.

24. Gam AN, Warming S, Larsen LH, Jensen B, Høydalsmo O, Allon I, et al. Treatment of myofascial trigger-points with ultrasound combined with massage and exercise--a randomised controlled trial. Pain. 1998;77:73-9.

25. Carlson CR, Bertrand PM, Ehrlich AD, Maxwell AW, Burton RG. Physical self-regulation training for the management of temporomandibular disorders. J Orofac Pain. 2001;15:47-55.

26. Lark MR, Gangarosa LP Sr. Iontophoresis: an effective modality for the treatment of inflammatory disorders of the temporomandibular joint and myofascial pain. Cranio. 1990;8:108.

27. Sluka KA, Deacon M, Stibal A, Strissel S, Terpstra A. Spinal blockade of opioid receptors prevents the analgesia produced by TENS in arthritic rats. J Pharmacol Exp Ther. 1999;289:840-6.

28. Dundar U, Evcik D, Samli F, Pusak H, Kavuncu V. The effect of gallium arsenide aluminum laser therapy in the management of cervical myofascial pain syndrome: a double blind, placebo-controlled study. Clin Rheumatol. 2007;26:930-4.

29. Manfredini D, Landi N, Tognini F, Orlando B, Bosco M. Muscle relaxants in the treatment of myofascial face pain. A literature review. Minerva Stomatol. 2004;53:305-13.

30. Vignolo V, Vedolin GM, de Araujo Cdos R, Rodrigues Conti PC. Influence of the menstrual cycle on the pressure pain threshold of masticatory muscles in patients with masticatory myofascial pain. Oral Surg Oral Med Oral Pathol Oral Radiol Endod. 2008;105:30815 . 